\title{
Reversible pulmonary hypertension in sarcoidosis
}

\author{
J. DAVIES \\ M. NeLlen \\ M.R.C.P. \\ M.D., F.R.C.P. \\ J. F. GoodwIN \\ M.D., F.R.C.P., F.A.C.C. \\ Division of Cardiovascular Disease, (Department of Medicine), Royal Postgraduate Medical \\ School, Hammersmith Hospital, London, W12 OHS
}

\begin{abstract}
Summary
A young man presented with severe pulmonary hypertension and was found to have extensive pulmonary sarcoidosis. Following treatment with corticosteroids, his lung infiltration improved radiologically and his pulmonary artery pressure fell. This improvement has been maintained for 6 years, and when last investigated his pulmonary artery pressure was normal.
\end{abstract}

\section{Case history}

A 33-year-old Ghanaian suddenly developed extreme dyspnoea while travelling by air from New York to London. His dyspnoea started following take-off, and was greatly improved by oxygen therapy. On admission to hospital in London he complained of slight, but progressive, exertional dyspnoea which had been present for the preceding four months. He had a dry cough and had lost one stone in weight over this period.

On examination, he was a thin, ill-looking man who was very orthopnoeic with a resting respiratory rate of $50 / \mathrm{min}$. He was afebrile and did not have cyanosis or clubbing of the fingers. He had reduced air entry bilaterally and scattered inspiratory crepitations. There was an easily palpable parasternal heave and loud pulmonary component to the second heart sound on auscultation, but there was no right heart failure. He had an audible right ventricular third heart sound, but no heart murmurs, a palpable spleen and diffuse non-tender lymphadenopathy. Blood gases at this time showed hypoxia $\left(\mathrm{PO}_{2}=5 \cdot 1\right.$ $\mathrm{kPa}, 38 \mathrm{~mm} \mathrm{Hg})$ and hypercapnia $\left(\mathrm{PCO}_{2}=6.2 \mathrm{kPa}\right.$, $46 \mathrm{~mm} \mathrm{Hg}$ ). Haemoglobin estimation and white cell count were normal. Serum calcium levels were normal, but there was mild hyperuricaemia. Immunoglobulins showed mild elevation in IgG and IgM. Mantoux test, at a dose of $1: 1000$, was negative and sputum cultures for mycobaeteria were negative. Inguinal node biopsy revealed the classical histological features of sarcoidosis.
The electrocardiogram showed sinus rhythm with a QRS axis of $+120^{\circ}$ and a large $P$ wave in standard lead 2 suggestive of right atrial hypertrophy. Chest $\mathrm{X}$-ray (Fig. 1) showed confluent nodular shadowing throughout both lung fields while his heart size appeared normal. Pulmonary function was very poor with an $\mathrm{FEV}_{1}$ of 0.7 litres and a FVC of 0.9 litres, giving an $\mathrm{FEV}_{1} / \mathrm{FVC}$ ratio of $78 \%$ (Table 1 ). Right heart catheterization was performed at this time (Table 2) and showed marked pulmonary hypertension.

Treatment was started with prednisolone at a dose of $60 \mathrm{mg}$ daily, with considerable symptomatic im provement. Within 10 days he was able to walk? across the ward and after 6 weeks he could walk more than a mile on the flat. Four months later when reassessed he was well and asymptomatic on prednisolone $15 \mathrm{mg}$ daily. Full examination was normal. The electrocardiogram was unchanged and the chest X-ray showed considerable clearing of his pulmonary infiltration. Pulmonary function tests were still abnormal showing a severe restrictive defect (Table 1) but there had been some improvement in lung volumes. Further right heart study (Table 2) showed persisting pulmonary hypertension, but with a definite decrease in pulmonary artery pressure. He continued well and stopped taking steroids after a further two months.

Six years later when he returned to London he reported that he had remained well and asymptomatic. Respiratory function tests were still abnormal (Table 1), but his chest X-ray now showed much less pulmonary shadowing. A lung scan confirmed defects of ventilation and perfusion involving the upper lobes of both lungs. His electrocardiogram still showed right axis deviation, but was otherwise normal.

He agreed to further cardiac catheterization which now demonstrated virtually normal right heart pressure at rest and after exercise (Table 2). He has remained well and asymptomatic since. 


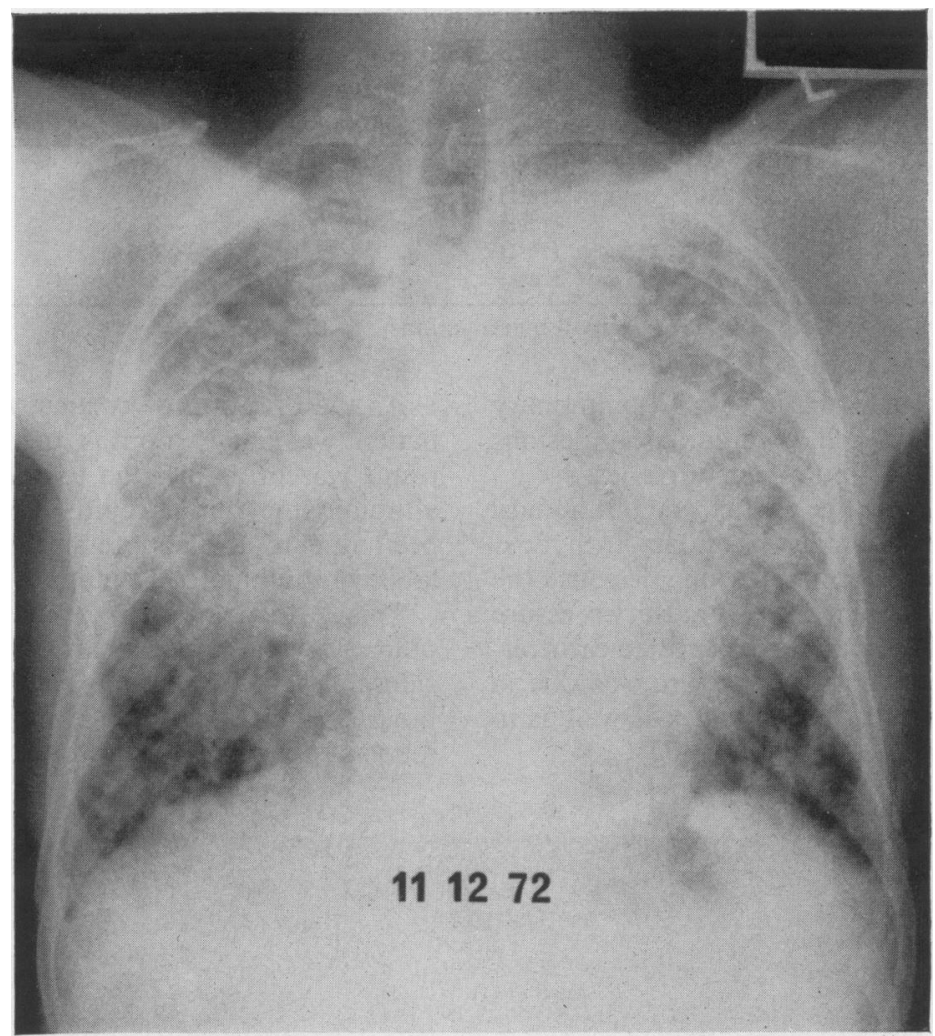

FIG. 1. Chest X-ray appearance at time of diagnosis in 1972 showing extensive nodular shadowing throughout both lungs. Heart size appeared normal.

\section{Discussion}

Pulmonary hypertension is a known complication of pulmonary sarcoidosis (Svanborg, 1961; Rizzato et al., 1980), but it is not well recognized that the pulmonary artery pressure may return to normal following treatment. Indeed, McClement et al. (1953) found no improvement in pulmonary hypertension in 10 patients following steroid therapy, suggesting that the pulmonary hypertension was due to established lung fibrosis.

On the other hand, sarcoidosis can be associated with severe pulmonary vasculitis with relatively little involvement of alveolar tissue, and can result in death from cor pulmonale without extensive lung fibrosis (Levine, Saldana and Hutter, 1971). This complication of sarcoidosis may be responsive to steroids.

Battesti, Basset and Saumon (1978) reported a pathological study of one patient who had died as a result of pulmonary hypertension where at postmortem numerous calcified glands compressing proximal pulmonary arteries were discovered and the walls of the pulmonary vessels were invaded by sarcoid granulomas. Michaels, Brown and Cory-

TABle 1. Pulmonary function tests

\begin{tabular}{lcccc}
\hline & $\begin{array}{c}\mathrm{FEV}_{1} \\
\text { (litres) }\end{array}$ & $\begin{array}{c}\text { FVC } \\
\text { (litres) }\end{array}$ & FEV $/ F V C_{1}$ & $\begin{array}{c}\text { KCO } \\
\text { (predicted } \\
\text { normal 1.4-1.9) }\end{array}$ \\
\hline 1. At diagnosis & 0.7 & 0.9 & $78 \%$ & $\begin{array}{c}\text { Too } \\
\text { dyspnoeic } \\
\text { to co-operate } \\
1.43\end{array}$ \\
$\begin{array}{l}\text { 2. Three months later } \\
\text { 3. Six years later }\end{array}$ & 1.3 & 1.5 & $87 \%$ & 1.73 \\
\hline
\end{tabular}


TABLE 2. Right heart catheterization results

\begin{tabular}{|c|c|c|c|c|c|}
\hline & & & $\begin{array}{c}\text { Right ventricle } \\
\text { pressure } \\
(\mathrm{mmHg})\end{array}$ & $\begin{array}{l}\text { Pulmonary } \\
\text { artery pressure } \\
(\mathrm{mmHg})\end{array}$ & $P_{\mathrm{O}_{2}}(\mathrm{mmHg})$ \\
\hline 1. At diagnosis & $\begin{array}{l}\text { Air } \\
50 \% \text { oxygen }\end{array}$ & $\begin{array}{l}\text { (rest) } \\
\text { (rest) }\end{array}$ & $\begin{array}{l}70 / 5 \\
50 / 5\end{array}$ & $\begin{array}{l}70 / 35 \\
50 / 25\end{array}$ & $\begin{array}{r}56 \\
200\end{array}$ \\
\hline 2. Three months later & $\begin{array}{l}\text { Air } \\
50 \% \text { oxygen }\end{array}$ & $\begin{array}{l}\text { (rest) } \\
\text { (rest) }\end{array}$ & $\begin{array}{l}40 / 7 \\
38 / 6\end{array}$ & $\begin{array}{l}40 / 18 \\
38 / 13\end{array}$ & $\begin{array}{r}93 \\
240\end{array}$ \\
\hline 3. Six years later & Air & (rest) & $28 / 3$ & $28 / 10$ & 93 \\
\hline
\end{tabular}

Pulmonary wedge pressures normal in all investigations

Wright (1960) reported two cases of pulmonary sarcoidosis where giant cell granulomatous lesions were found in branches of pulmonary arteries.

Although part of this patient's pulmonary hypertension was undoubtedly secondary to hypoxaemia caused by his widespread lung lesions, the relatively small decrease in pulmonary artery pressure following oxygen administration at cardiac catheterization suggests that the raised pressure was due in part to structural vascular bed changes as well as to alveolar hypoxaemia.
As the duration of corticosteroid therapy in this patient was only 6 months, the favourable long-term result was probably due to spontaneous resolution although the initial rapid improvement may have been due to the suppressive effect of steroids on labile granulomatous changes.

This case demonstrates that steroid therapy in pulmonary sarcoidosis can be associated with considerable fall in pulmonary artery pressure in combination with symptomatic improvement. Although much of this patient's improvement was undoubtedly

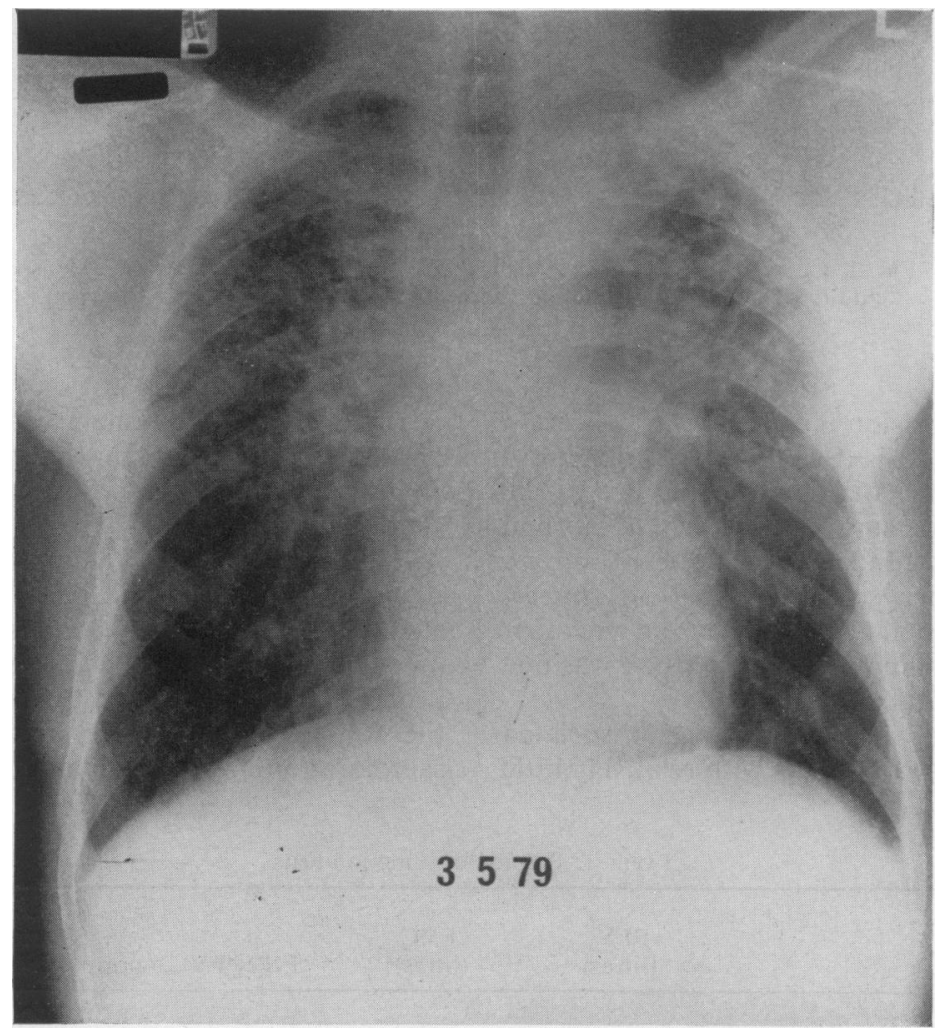

Fig. 2. Chest X-ray taken when last seen in 1979 showing considerable clearing of the diffuse lung shadowing with persisting patchy opacities in both upper zones. Heart size remains normal. 
due to resolution of granulomas in the lung acini, it is likely that involvement of pulmonary arteries was an important additional factor. The purpose of this report is to emphasize that sarcoidosis can involve the pulmonary vasculature, causing pulmonary hypertension, which can be reversible and may respond to corticosteroid treatment.

\section{Acknowledgments}

We are grateful to Professor J.G. Scadding for helpful comments and criticism, and to Professor R. Steiner for reviewing the chest $\mathrm{X}$-rays.

\section{References}

Battesti, J.P., Bassett, G.F. \& Sauman, G. (1978) Chronic corpulmonale in pulmonary sarcoidosis. Thorax, 33, 76.
Levine, B.W., Saldana, M. \& Hutter, A.M. (1971) Pulmonary hypertension in sarcoidosis. American Review of Respiratory Diseases, 103, 413.

McClement, J,, Renzetti, A., Himmelstein, A. \& CourNAND, A. (1953) Cardiopulmonary function in the pulmonary form of Boek's sarcoid and its modification by cortisone therapy. American Review of Tuberculosis and Pulmonary Diseases, 67, 154.

Michaels, L., Brown, N.J. \& CoRy-Wright, M. (1960) Arterial changes in pulmonary sarcoidosis. Archives of Pathology, 69, 741.

Rizzato, G., Bertoli, L., Merlini, R., Tansini, G., Scoccia, S., Mantero, O. \& Conti, F. (1980) L'ipertensione arteriosa polmonare nella sarcoidosi. Giornale italiano di cardiologia, 10, 309.

SvanborG, N. (1961) Studies on the cardiopulmonary function in sarcoidosis. Acta medica scandinavica, 366, (Suppl. 39). 